\title{
GÊNERO E EDUCAÇÃO DE JOVENS E ADULTOS: NOVO OLHAR PARA A EDUCAÇÃO FÍSICA ESCOLAR
}

\author{
GENDER AND YOUTH AND ADULT EDUCATION: \\ NEW VIEW FOR SCHOOL PHYSICAL EDUCATION \\ GÉNERO Y EDUCACIÓN DE JÓVENES Y ADULTOS: \\ NUEVA MIRADA A LA EDUCACIÓN FÍSICA ESCOLAR
}

\author{
LuCAS BAPTISTA MOUSINHO LinS ${ }^{1}$ \\ Rosa Malena de Araújo Carvalho ${ }^{\mathrm{I}}$ \\ ${ }^{\text {I }}$ Universidade Federal Fluminense (UFF), Niterói/RJ - Brasil
}

Resumo Este artigo apresenta a pesquisa que problematizou como o tema gênero está presente em algumas orientações curriculares municipais do Estado do Rio de Janeiro direcionadas à Educação de Jovens e Adultos (EJA). A EJA é uma modalidade da educação ofertada àqueles e àquelas que não tiveram oportunidades de concluir a educação básica na idade considerada regular. Como professores formados em educação física, atentos às questões relacionadas ao corpo como uma construção cultural, buscamos identificar como o gênero é abordado no ambiente escolar, enquanto tema transversal de uma educação que procura constituir uma sociedade justa e igualitária. A metodologia adotada foi a revisão de literatura, em especial a análise documental de leis e diretrizes/orientações curriculares nacionais e de três municípios da região metropolitana - Tanguá, Rio de Janeiro e Belford Roxo - do Estado do Rio de Janeiro. Destacando a importância de referências que promovam a organização do trabalho docente, concluímos que, de forma geral, as diretrizes/ orientações curriculares da EJA possibilitam a abordagem desse tema no âmbito escolar, mesmo que de maneira indireta. E, que as aulas de educação física podem contribuir de forma significativa na transformação de uma sociedade com valores excludentes em oportunidades para todos e todas.

Palavras-chave: Gênero; EducaÇão de Jovens e Adultos; Educação Física escolar.

ABSTRACT This article presents a research that problematized how the gender theme is present in some municipal curricular guidelines of the State of Rio de Janeiro directed to Youth and Adult Education (EJA). EJA is a modality of education offered to those who did 
not have opportunities to complete basic education at the age considered regular. As teachers graduated in physical education, attentive to issues related to the body as a cultural construction, we seek to identify how gender is addressed in the school environment, as a transversal theme of an education that seeks to constitute a fair and egalitarian society. The methodology adopted was the literature review, in particular the documentary analysis of laws and national curriculum guidelines/orientations and three municipalities in the metropolitan region - Tanguá, Rio de Janeiro and Belford Roxo - of the State of Rio de Janeiro. Highlighting the importance of references that promote the organization of teaching work, we conclude that, in general, the curriculum guidelines/orientations of EJA allow the approach of this theme in the school environment, even if in an indirect way. And that physical education classes can significantly contribute to transforming a society with exclusive values into opportunities for all.

Keywords: Gender; Youth and Adult Education; School Physical Education.

RESUMEN Este artículo presenta una investigación que problematizó cómo el tema de género está presente en algunos lineamientos curriculares municipales del Estado de Río de Janeiro dirigidos a la Educación de Jóvenes y Adultos (EJA). EJA es una modalidad de educación ofrecida a aquellos que no tuvieron oportunidades de completar la educación básica en la edad considerada regular. Como maestros capacitados en educación física, buscamos identificar cómo se aborda el género en el ámbito escolar, como tema transversal de una educación que busca constituir una sociedad justa e igualitaria. La metodología adoptada fue la revisión de la literatura, en particular el análisis documental de leyes y lineamientos/orientaciones curriculares nacionales y tres municipios de la región metropolitana - Tanguá, Rio de Janeiro y Belford Roxo - del Estado de Rio de Janeiro. Destacando la importancia de los referentes que favorezcan la organización del trabajo docente, llegamos a la conclusión de que, en general, los lineamientos/orientaciones curriculares de EJA permiten el abordaje de este tema en la escuela, aunque indirectamente. Y que las clases de educación física pueden contribuir significativamente a transformar una sociedad con valores exclusivos en oportunidades para todos.

Palabras Clave: Género; Educación de jóvenes y adultos; EduCACión física escolar.

\section{INTRODUÇÃo}

Observando o cotidiano da formação e a atuação na educação básica, as tensões provocadas pela relação entre os gêneros sempre chamaram a atenção, especialmente quando a docência encontra nas práticas corporais seu objeto de estudos, buscando problematizar e refletir sobre as questões sociais presentes no âmbito escolar.

Segundo Scott (1995), o termo gênero designa as relações sociais entre os sexos, indicando as construções que sociedade e cultura, em dado período histórico, atribuem ao masculino e feminino, isto é, ideias e papéis de homens e mulheres.

Ao longo dos anos, conceitos e concepções acerca desse tema sofreram diversas modificações e, cada vez mais, identificamos a necessidade e importância dos debates e estu- 
dos para se pensar as relações de gênero, com a perspectiva de construir meios de incluir reflexões e práticas dentro das aulas, incentivando um olhar crítico dos/as alunos/as em relação a esse tema.

O gênero, ao enfatizar o caráter fundamentalmente social das divisões baseadas no sexo, possibilita perceber as representações e apresentações das diferenças sexuais. Destaca, ainda, que imbricadas às diferenças biológicas existentes entre homens e mulheres estão outras social e culturalmente construídas (SOUSA; ALTMANN, 1999, p. 3)

Falar em gênero significa colocar o corpo e suas marcas, culturalmente construídas, em discussão. Idade, etnia, cor da pele, peso e altura corporal, dentre outras, não estão apenas no âmbito da biologia e da anatomia. A antropologia, a filosofia e a história propõem inúmeras produções que auxiliam a entender significados dos contextos em tudo que é atribuído ao corpo. Ao situar o corpo em sua realidade histórica, cultural e, portanto, social, percebemos que as formas de conhecer o corpo estão inseridas nas relações e sentidos sociais. Em uma sociedade em que as desigualdades estão acentuadas, afirmar a diversidade corporal pode significar enfraquecer o conceito de corpo-objeto (BRUHNS, 1999) que constitui uma organização social como a nossa (cujas principais características deste sistema estão associadas ao rendimento, às normas de comparação, idealizando o princípio de sobrepujar, à regulamentação rígida, à racionalização dos meios e técnicas - mantendo e reproduzindo disparidades e hierarquias sociais).

Aproximando essas ideias do processo de escolarização, destacamos a EJA (Educação de Jovens e Adultos) por ser uma modalidade da educação básica que busca oportunizar àqueles/as que, durante sua vida, não puderam iniciar ou completar sua formação na escola, na idade considerada apropriada, por vários motivos, como: trabalho, família, dificuldade financeira, entre outros. Essa modalidade da educação permite que o/a aluno/a possa terminar os estudos em condições apropriadas ao mundo do jovem e do adulto, o qual requer outro tempo, possibilitando uma formação humana, assim como melhor qualificação profissional e, consequentemente, mais e melhores oportunidades no mundo do trabalho.

A EJA é caracterizada por uma diversidade cultural presente nas aulas, em que geralmente são pessoas com diferenças de idade, podendo ser jovens, adultos/as e idosos/as na mesma turma, com objetivos muitos distintos uns/umas dos/as outros/as, cada um/a com sua própria história de vida. Essa diversidade é o que faz a EJA ser tão rica, pelas inúmeras possibilidades de experiências e, ao mesmo tempo, exige um preparo diferenciado dos/as profissionais que lá trabalham, pela complexidade que essa heterogeneidade provoca.

Os debates e regulamentações referentes à EJA se iniciaram de maneira concreta a partir da promulgação da Constituição Federal de 1988, esboçando a ideia inicial do que viria a ser a EJA, definindo no art. 208 (emenda constitucional no 59, 2009) que é dever do Estado garantir "educação básica obrigatória e gratuita dos 4 aos 17 anos de idade, assegurada inclusive sua oferta gratuita para todos os que a ela não tiveram acesso na idade própria".

Anos depois, em 1996, a Lei de Diretrizes e Bases (LDB), lei nº 9.394, menciona na seção $\mathrm{V}$, no art. 37 que a educação de jovens e adultos "será destinada àqueles que não tiveram acesso ou continuidade de estudos nos ensinos fundamental e médio na idade própria 
e constituirá instrumento para a educação e a aprendizagem ao longo da vida", mostrando a importância da EJA na sociedade, mesmo que ainda não existisse uma diretriz curricular específica para essa modalidade da educação.

O Parecer CNE/CEB n ${ }^{\circ}$ 11/2000 vem ao encontro dessa necessidade e dispõe sobre as diretrizes curriculares nacionais para a Educação de Jovens e Adultos, trazendo o histórico e orientado a execução dessa modalidade da educação básica nas etapas do ensino fundamental e médio, a qual expressa uma especificidade própria, devendo ser dada a devida atenção.

Esse Parecer também é fruto das muitas dúvidas relacionadas à EJA, pela confusão com o antigo supletivo, solicitando informações ao Conselho Nacional de Educação (CNE). Assim sendo, este Parecer se ocupou das diretrizes da EJA. Observamos, então, que a EJA ainda era muito introdutória e vaga, precisando ainda de uma legislação própria que regesse essa modalidade da educação. Como os/as alunos/as eram enviados/as por faixas etárias aos exames supletivos, a idade mínima para a inscrição e realização desses exames de conclusão do ensino fundamental era de 15 anos completos e, para o ensino médio, os/ as alunos/as deveriam ter 18 anos completos.

O Parecer CNE/CEB n 11/2000 (BRASIL, 2000), então, nos diz que "a EJA é uma categoria organizacional constante da estrutura da educação nacional, com finalidades e funções específicas" (p. 5). Essas funções têm por objetivo proporcionar e auxiliar os/as alunos/as em sua formação e divididas em três, que são:

a) Função Reparadora: "significa não só a entrada no circuito dos direitos civis pela restauração de um direito negado: o direito a uma escola de qualidade, mas também o reconhecimento daquela igualdade ontológica de todo e qualquer ser humano" (p. 7), isto é, possibilitar mudança na dura realidade do sujeito, a qual é fruto de uma sociedade injusta e desigual;

b) Função Equalizadora: significa a reentrada no sistema educacional dos que tiveram uma interrupção forçada, seja pela repetência, pela evasão ou por qualquer motivo. Isto é, possibilitar a esses sujeitos oportunidades no mundo do trabalho, na vida social e na abertura dos canais de participação de modo a auxiliar na constituição de uma sociedade com mais igualdade e equidade social;

c) Função Qualificadora: tem como base potencializar o desenvolvimento e a adequação de atualização em quadros escolares ou não escolares, é um apelo para a educação permanente e criação de uma sociedade educada para o universalismo, a solidariedade, a igualdade e à diversidade, isto é, significa propiciar a todos condições para a produção e a atualização de conhecimentos por toda a vida.

Em 2010, entrou em vigor a Resolução CNE/CEB n ${ }^{\circ}$ 03, que em seu art. 3 endossa de forma clara qual é a finalidade da EJA, pois diz que

Art. 3. A presente Resolução mantém os princípios, os objetivos e as Diretrizes formulados no Parecer CNE/CEB n ${ }^{\circ} 11 / 2000$, que estabeleceu as Diretrizes Curriculares Nacionais para a Educação de Jovens e Adultos e, quanto à Resolução CNE/CEB n $n^{\circ} 1 / 2000$, amplia o alcance do disposto no artigo $7^{\circ}$ para definir a idade mínima também para a frequência em cursos de EJA, bem como substitui o termo "supletivo" por "EJA" (...) (BRASIL, 2010, p. 1) 
Assim, nota-se que a EJA, enquanto parte do direito à educação, é uma modalidade recente. Levando em consideração que a LDB incluiu a EJA na educação brasileira não tem três décadas, é possível perceber que ainda há muitos pontos importantes e interrogações a serem discutidas nesse meio.

Em 2010, aconteceu a Conferência Nacional de Educação (CONAE), que foi um espaço democrático aberto pelo Poder Público e articulado com a sociedade para que todos/as pudessem participar do desenvolvimento da Educação Nacional. Nessa conferência, foi desenvolvido um documento muito importante voltado para constituir em espaço social de discussão da educação brasileira. Em um dos eixos que compõe esse documento - o eixo VI - tem como tema Justiça Social, Educação e Trabalho: Inclusão, Diversidade e Igualdade, abordando e ampliando de forma crítica questões que envolvem a diversidade e justiça social, buscando debater políticas educativas que abram para o princípio da equidade. Em 2014, houve outra CONAE, tendo como princípio reafirmar os ideais apresentados. Hoje, em 2020, em contexto tão adverso para uma população que luta por dignidade da vida, retomar esses documentos expressa nosso compromisso com um trabalho docente pautado na consideração de que a educação é um direito social. O que vem ao encontro da proposta desse artigo.

A Base Nacional Comum Curricular (BRASIL, 2018) é um documento normativo que entra em vigor no ano de 2018, como tentativa de novo norte à educação brasileira. É um documento que, em suas primeiras versões, abordou tanto a EJA quanto as questões de gênero. Contudo, a versão atual homologada, além de não tratar de assuntos relacionados à EJA e suas especificidades, retirou os termos "gênero e orientação sexual" do texto, o que faz gerar reflexões sobre essa atitude, que é totalmente contrária à concepção de educação e toda legislação aqui apresentada.

Considerando as características da EJA, um dos pontos a serem discutidos sobre a diversidade presente nesse modo de fazer a escolarização acontecer, refere-se às questões de gênero presentes nesse contexto. Visto que essa modalidade da educação possui uma diversidade e pluralidade cultural vasta, traduzida nas histórias dos seus sujeitos, marcadas nos corpos, pela etnia, cor da pele, idade e gênero - que é o enfoque desse trabalho. Falar das questões de gênero na escola é fundamental pelo fato de que vivemos em uma sociedade de grande diferença e desigualdade, principalmente por se tratar de uma sociedade com conceitos e concepções machistas. Por exemplo, as diferenças e desigualdades no mundo do trabalho, no que diz respeito ao tratamento dado às mulheres e aos homens, bem como as funções que ocupam e suas respectivas remunerações. Assim, o tema gênero se torna importante no âmbito escolar, uma vez que ajudará a proporcionar uma visão mais ampla e crítica dos assuntos acerca dessa temática, visto que o público da EJA, em sua maioria, além de estar ou querer estar no mundo de trabalho, buscando oportunidades, tem experiências relacionadas ao contexto do adulto, como a responsabilidade que significa construir e cuidar da família.

Dessa forma, o objetivo geral dessa pesquisa foi problematizar se/como as questões de gênero estão presentes em três orientações curriculares municipais do Estado do Rio de Janeiro da EJA, em especial, na educação física - prática pedagógica de formação e atuação profissional dos autores desse artigo. Identificando os motivos que levam o tema gênero a ser ou não incluído nas três orientações curriculares municipais estudadas, promovendo breve reflexão sobre o que causa a dicotomia dos gêneros na escola, especialmente na EJA. 
A metodologia desse trabalho foi a revisão de literatura e análise documental, buscando identificar nas três orientações curriculares municipais estudadas, se/como o tema gênero é incluído e abordado dentro das aulas de educação física. As orientações curriculares municipais relacionadas à EJA, aqui analisadas foram dos municípios do Rio de Janeiro, Belford Roxo e Tanguá, todos da região metropolitana do Estado - cujas orientações foram apresentadas no Curso de Extensão corporeidades, práticas corporais e educação de jovens e adultos (EJA) da Universidade Federal Fluminense.

Considerando a diferenciação e a especificidade de cada contexto, colocando o gênero como problema a enfrentar, concordamos com Minayo (2001) quando nos indaga como poderíamos priorizar a partilha de princípios e não de procedimentos. Essa ideia se aproxima da proposta desse artigo, quando apresenta, contextualiza, interroga alguns dos indicativos que auxiliam a compreender a inserção do tema gênero no exercício da docência.

\section{A EJA E A EDUCAÇÃo FíSICA ESCOLAR}

A educação física escolar é entendida como um componente curricular obrigatório da educação básica, que busca proporcionar aos/às alunos/as conhecimentos e vivências da cultura corporal, por meio dos jogos, dos esportes, das lutas, das ginásticas, das danças e das práticas corporais de aventura, com o intuito de auxiliar na formação de sujeitos críticos, autônomos e transformadores, para que possam exercer seu papel de cidadãos/ãs, o que inclui identificar e buscar as condições sociais necessárias para uma melhor qualidade de vida. Antunes e Gebran (2010) destacam o esforço dos professores e professoras de educação física, para incluir o corpo e as práticas corporais nos currículos que dialogam com a realidade social.

O primeiro documento oficial que regulamenta a educação física na EJA foram as Orientações Curriculares do Ministério da Educação e Cultura (MEC) (BRASIL, 2000). Esse documento foi proposto em 2000, embasado na Constituição Federal de 1988, na LDB (BRASIL, 1996) e, nos PCNs (BRASIL, 1997).

A LDB de 1996, estabelece no art. 26 que a educação física, integrada à proposta pedagógica da escola, é um componente obrigatório da educação básica, a qual é constituída por três etapas: educação infantil, ensino fundamental e médio. A respeito da base comum nacional dos currículos do ensino fundamental e médio, a LDB diz que a educação física deve ser ajustada às faixas etárias e às condições da população escolar, sendo facultativa nos cursos noturnos - justamente em que o alunado é basicamente constituído pelo público da EJA, composto por estudantes que trabalham o dia inteiro, possuem e sustentam suas famílias.

A Lei nº 9.394/96 dispõe para a Educação Básica:

Art. 26. Os currículos do ensino fundamental e médio devem ter uma base nacional comum, a ser complementada, em cada sistema de ensino e estabelecimento escolar, por uma parte diversificada, exigida pelas características regionais e locais da sociedade, da cultura, da economia e da clientela.

- $\quad$ §o A Educação Física, integrada à proposta pedagógica da escola, é componente curricular obrigatório da educação básica, sendo sua prática facultativa ao aluno: (Redação dada pela Lei $\mathrm{n}^{\circ} 10.793$, de $1^{\circ} .12 .2003$ )

- que cumpra jornada de trabalho igual ou superior a seis horas; 
- maior de trinta anos de idade;

- que estiver prestando serviço militar inicial ou que, em situação similar, estiver obrigado à prática da educação física;

- $\quad$ que tenha prole (BRASIL, 1996)

Essas indicações anteriores, portanto, não favorecem a presença dos/as alunos/as da EJA nas aulas de educação física e, ao mesmo tempo, indicam uma educação física baseada em performance e rendimento (o que cansaria, ainda mais, os/as trabalhadores/as que chegam às escolas após um dia exaustivo de trabalho).

A BNCC (BRASIL, 2018) ratifica a educação física no processo da educação básica, mas é um documento que não apresenta, tampouco coloca em debate a EJA. É importante ressaltar tal fato pois esse documento é colocado como importante para a atual educação brasileira, indicando os rumos educacionais do país e, ao não abordar as questões da EJA indica uma situação preocupante. Revela que, para esses/as jovens e adultos/as, a educação não é direcionada como um direito.

Junto disso, além de identificar o não favorecimento do acesso à educação, por àqueles/as que estão fora da idade considerada regular, é perceptível a educação física escolar na EJA não valorizada pelas leis educacionais. Mesmo com essa disciplina sendo obrigatória e trazendo elementos relevantes para ser contribuir com a formação, pela educação básica, do/a cidadão/ã crítico/a, reflexivo/a e autônomo/a, onde a abordagem das práticas corporais pela perspectiva da cultura corporal (COLETIVO DE AUTORES, 1992) enfatiza a importância de identificar essas práticas corporais como produções sócio históricas. Ou seja, os jogos, as danças, as brincadeiras, as lutas etc., como conhecimentos socialmente produzidos, e o papel que a educação física escolar tem perante os/as alunos/as - de proporcionar a aprendizagem desses conteúdos mencionados - não são considerados, pois essa prática pedagógica acaba sendo facultativa e, na prática, não sendo oferecida.

$\mathrm{O}$ que revela a desconsideração com o direito a uma educação plena e, ao mesmo tempo, demonstra uma concepção de educação física preocupada com rendimento atlético esportivo e, por isso, prejudicial ao alunado da EJA. Em outra perspectiva, pela ideia de cultura corporal, a educação física escolar pode organizar as práticas corporais por grupos de conteúdos: os jogos, as danças, as lutas, as ginásticas, os esportes, as brincadeiras, as práticas corporais de aventura e demais produções corporais historicamente construídas e organizadas (CARVALHO, 2017).

Ao expressar uma concepção de educação física que não considere os contextos, apenas o condicionamento físico, a legislação produz uma das dificuldades que os/as professores/as de educação física encontram nas escolas relacionadas à EJA, uma vez que têm que ampliar esforços para pensar diferentes métodos e maneiras de atrair esses/as alunos/ as e, com intencionalidade pedagógica, contribuir de forma significativa na formação dos mesmos e, consequentemente, na realidade vivida por eles/as.

Lidar com diferenças sociais e culturais construídas e colocá-las em debate, em uma realidade que exclui as diferenças, acaba sendo uma tarefa complicada. A aula de educação física, quando organizada pela perspectiva da cultura corporal, é um espaço propício para esse debate, pois é o momento que a dicotomia entre gêneros fica mais evidente, podendo ser pedagogicamente abordada. Essa dicotomia pode ser expressa em situações, como na fala de Oliveira e Votre (2006), onde 
O sentir-se rejeitada nas aulas de educação física é facilmente explicável, pois a disciplina, até bem pouco tempo (e ainda hoje), se pautava por um modelo reducionista em que o corpo, a aptidão física e o desempenho eram os objetivos mais importantes. Nesse quadro, não havia espaço para as meninas 'baixinhas e frágeis', sobretudo quando a essas características somava-se a falta de habilidade; elas não tinham vez, não jogavam e nem praticavam esportes com suas colegas meninas e muito menos com os meninos. A prática esportiva privilegiava aquelas que tinham um bom desempenho e que eram aptas a praticar aquelas modalidades esportivas associadas à velocidade, força, impacto e resistência (op. cit., p. 182)

Isso permite entender a sociedade em que vivemos, uma sociedade machista que não valoriza aspectos ditos femininos como cooperação, coletivo, participação, solidariedade, respeito. O privilégio ao masculino, portanto, se reflete na sociedade e pode ser identificado nas atividades corporais das aulas de educação física, principalmente nos esportes, onde fica claro, quando Altmann (2015) diz que “(...) o esporte é um meio dos meninos exercerem um domínio de espaço na escola" (p. 76). O que mostra como é relevante o papel do/a professor/a em problematizar e direcionar as questões presentes na prática esportiva, chamando a atenção dos/as alunos/as para valores sociais importantes, como a educação para uma boa convivência entre os gêneros.

Segundo Pereira e Devide (2008), é fundamental trabalhar essas situações de forma crítica, refletindo e questionando alguns valores como o respeito e igualdade de gênero, desconstruindo preconceitos e exclusão dos/as alunos/as nas aulas, identificando como essas situações são produzidas. Assim, o esporte pode ser um dos elementos para proporcionar e enfatizar os debates sobre questões de gênero.

Os PCNs (BRASIL, 1997) defendem a inclusão da temática dentro das escolas, através do projeto político pedagógico, onde os/as educadores/as têm oportunidade de interagir com os/as alunos/as, de uma forma esclarecedora, para tratar desse assunto que é tão importante para a construção de sua identidade, pois passa por questões culturais e de afeto. A proposta dos PCNs legitima o papel dos/as educadores/as nessa área. Além dos PCNs, outras bases legais da educação enfatizam as questões de gênero, mesmo que de forma indireta, nas escolas, como mencionados logo abaixo.

A LDB - Lei 9394/96 (BRASIL, 1996), em seu art. $3^{\circ}$, afirma que o ensino deverá ser ministrado com princípios baseados no respeito à liberdade e apreço a um bom convívio, mostrando que aprender a lidar com as diferenças deve ser lecionado na escola para uma formação em que discriminações e exclusões não ocorram. O que vai ao encontro da Constituição Federal de 1988, quando no Art. $3^{\circ}$ define, entre os objetivos fundamentais da República Federativa do Brasil, construir uma sociedade livre, justa e solidária e promover o bem de todos/as, sem preconceitos de origem, raça, sexo, cor, idade e quaisquer outras formas de discriminação.

Além desses, as Conferências Nacionais de Educação (CONAEs) de 2010 e de 2014 apresentaram diversos eixos, metas e objetivos para as discussões de gênero no ambiente escolar, buscando propor uma educação democrática, com políticas educacionais eficientes, promovendo e estimulando a justiça social e a diversidade, superando as desigualdades historicamente construídas nesse país. Vale ressaltar que nos documentos das CONAEs é 
ressaltada a necessidade de implementação da efetivação dos temas por elas citados, no conjunto de políticas educacionais do Plano Nacional da Educação (PNE).

Destacamos preocupação quanto aos documentos atuais, base da educação brasileira. O PNE (BRASIL, 2014) em nenhuma das suas metas previstas para a próxima década apresenta questões relacionadas à diversidade - muito menos as questões de gênero, em que houve um grande esforço de setores conservadores para obstruírem as discussões sobre gênero na escola. O que é um obstáculo, quando se defende o direito pleno à educação e, uma educação física que considera e contextualiza as práticas corporais à realidade conhecida pelos/as alunos/as (COLETIVO DE AUTORES, 1992), valorizando o respeito às diferenças e à diversidade, bem como propondo debates a fim de que os/as alunos/as reflitam, opinem e questionem situações experimentadas nas aulas, com o intuito de repensar e transformar suas atitudes, desenvolvendo o senso crítico.

Após estudar as orientações curriculares dos três municípios aqui mencionadas, concordamos com a existência de dois problemas centrais na discussão crítica da educação física escolar: desnaturalizar o que caracterizamos como corpo e, sair da forma esportiva que as práticas corporais hegemonicamente recebem (CARVALHO; CAMARGO, 2019).

O que pode contribuir com qualquer atuação docente e prática pedagógica que considere o corpo, em diálogo com a cultura e as experiências da vida em sociedade. Assim, trazer o gênero para discussão do fazer pedagógico significa expressar com qual ideia de educação e de corpo orientamos a organização do trabalho docente.

\section{A INCLUSÃo do TEMA GÊNERO NA EDUCAÇÃo FÍSICA ESCOLAR DA EJA}

Partindo desses pressupostos, para compreender a relação do tema gênero na EJA por meio das aulas de educação física, foi feita uma análise de orientações curriculares da EJA de três municípios do Estado do Rio de Janeiro, buscando verificar e compreender se/como o tema gênero é abordado nos currículos. Os municípios escolhidos para essa análise foram Tanguá, Belford Roxo e Rio de Janeiro, citados na metodologia desse trabalho.

Logo no início da leitura, algo chama a atenção: essas orientações são recentes, onde a primeira foi a do município do Rio de Janeiro, criada em 2010, tendo, portanto, uma década de existência. Esse fato enfatiza o quanto a modalidade EJA ainda está se constituindo e se fortalecendo.

A EJA tem uma diversidade e pluralidade cultural vasta, fazendo com que os/as professores/as precisem de uma percepção dessa realidade de forma ampla, compreendendo cada sujeito presente. Nessa perspectiva, essas orientações curriculares abordam e defendem uma sociedade plural e multicultural (BELFORD ROXO, 2012). A orientação curricular da EJA do município de Tanguá destaca, no art. 12, que os currículos da EJA devem-se adequar aos interesses, realidade e possibilidades da população a que se destinam (TANGUÁ, 2012).

Essas colocações evidenciam que as orientações curriculares entendem que o público da EJA é diversificado e, ponderam a relevância de levar em consideração esses aspectos, para englobar todos/as os/as estudantes, de uma forma ampla e crítica. A orientação curricular do município do Rio de Janeiro diz que não necessitamos entender o corpo desse 
público de forma descontextualizada, fragmentada, dividida em partes, hierarquizando, de acordo com a etnia, o gênero, a orientação sexual, a idade, entre outros aspectos (RIO DE JANEIRO, 2010).

Apesar de serem claras em suas colocações nas orientações curriculares para a EJA, foi percebido que, como exceção do município do Rio de Janeiro, nenhuma outra falou diretamente do tema transversal gênero. Os municípios de Tanguá e Belford Roxo abordam bastante a questão da diversidade, pluralidade, respeito, formação do/a cidadão/ã crítico/a e autônomo/a, assim como o município do Rio de Janeiro, porém os primeiros não relatam o termo gênero em nenhum dos seus documentos. A orientação curricular de Tanguá, na divisão dos conteúdos, menciona os ditos temas transversais, mas sem nenhuma especificação, dando a entender que se pode abordar o tema gênero nas aulas, mesmo que de forma indireta.

A orientação curricular do município do Rio de Janeiro da EJA aborda de forma clara e ampla aspectos considerados essenciais para lecionar nesta modalidade. Vale destacar que, além de mencionar todos os temas transversais dos PCNs (BRASIL, 1997), também é feita uma contextualização de cada um deles, explicando cada tema e o que representa para a formação do/a cidadão/ã reflexivo/a e crítico/a. Assim como as outras orientações, também se fala muito na questão da diversidade, porém é especificado no documento, onde diz que a diversidade (etnia, idade, gênero e sexualidade) é um dos eixos norteadores dos conteúdos a serem lecionados (RIO DE JANEIRO, 2010).

É importante ressaltar que as orientações curriculares municipais apresentadas são documentos que ainda não sofreram alterações em relação à $\mathrm{BNCC}$, sendo anteriores a mesma, em que foram embasadas por outros documentos, como os PCNs, que atualmente exercem pouca influência nas orientações da educação brasileira.

Portanto, colocar em prática a discussão de diversidade e pluralidade, especificadamente o tema gênero, não é algo simples e precisa de um olhar sensível aos contextos sociais, assim como de métodos e estudos que expressem compromissos com a população que constitui esse alunado. Analisando como essas orientações curriculares colocam essa discussão em questão, percebemos que alguns elementos da cultura corporal se repetem. Nessa forma, é possível fazer um levantamento de quais conteúdos são priorizados para auxiliar na implementação da discussão das questões de gênero na EJA, pelas aulas de educação física, problematizando a exclusão e o preconceito, incentivando a participação de todos/as nas atividades propostas.

Os assuntos mais citados foram os jogos cooperativos e coletivos, atividades rítmicas e expressivas, conhecimento do corpo, a ludicidade, a recreação, a modificação de regras oficiais dos esportes de acordo com as necessidades surgidas. Esse novo olhar da educação física escolar para a EJA é fundamental para acolher e incentivar o/a aluno/a a participar das aulas e contribuir, de forma significativa, para a reflexão do realizado e sua relação com o conjunto da sociedade. Pois, dentro dessa visão, pode-se identificar a história de cada prática corporal, suas modificações, o impacto que pode proporcionar para uma ajuda mútua, valorizando a importância do coletivo, a integração, a solidariedade, respeito às diferenças, a sociabilização e a inclusão. 
Pensando na lógica de exercer a docência com os assuntos encontrados nas orientações citadas, é importante ressaltar o papel das aulas co-educativas, uma vez que estas podem promover a igualdade e oportunidades para que todos/as possam participar das aulas de maneira ativa. Nessa perspectiva, Saraiva (1999) diz que a co-educação

Torna-se importante trazer para o campo das discussões e possibilidades pedagógicas as questões [...] como: os papéis sexuais estereotipados, os anseios irracionais de dominação dos homens, a opressão tradicional da mulher e, principalmente a ameaça ao direito de melhores condições e igualdade dos seres humanos no esporte e na educação física (op. cit., p. 181)

A utilização de práticas lúdicas nas aulas de educação física para tratar essa temática é um caminho para que todos/as os/as alunos/as possam vivenciar as atividades e participar de forma completa, sem medo e sem exclusão. Essa importância fica evidenciada na fala de Luckesi (2000), onde diz:

[...] o que a ludicidade traz de novo é o fato de que o ser humano, quando age ludicamente, vivencia uma experiência plena. [...] Enquanto estamos participando verdadeiramente de uma atividade lúdica, não há lugar, na nossa experiência, para qualquer outra coisa além desta atividade. Não há divisão. Estamos inteiros, plenos, flexíveis, alegres, saudáveis. [...] Brincar, jogar, agir ludicamente exige uma entrega total do ser humano, corpo e mente ao mesmo tempo (op. cit., p. 21)

Carvalho (2013) reforça a ideia da presença da ludicidade nas aulas de educação física, pois esta é uma das marcas da corporeidade presente na EJA, destacando que ao exercitar "a capacidade crítica, acreditamos que esse é um dos momentos em que o trabalho coletivo, desenvolvido nos cotidianos escolares, poderá ser potencializado pela contribuição da ludicidade nos processos de socialização e de aprendizagem" (op. cit., p. 42).

Os jogos cooperativos também podem ser um meio de possibilitar a união dos/ as alunos/as nas aulas e promover a participação como um todo, pois possuem uma estrutura onde os/as alunos/as jogam uns com os/as outros/as - e não contra os/as outros/as. Por isso, esses jogos são importantes, principalmente nas aulas de educação física, porque eles têm como objetivos diminuir a questão da competição acirrada e de comportamentos destrutivos, promover a interação de todos/as os/as participantes/as, assim como aflorar a espontaneidade, o prazer e alegria no participar. Dessa forma, os jogos cooperativos colaboram para que haja um envolvimento total dos/as alunos/as, eliminando o medo de fracassar e ainda, contribuindo para a criação da confiança em si mesmo e nos/as outros/as.

Os Jogos Cooperativos vêm com a intenção de compartilhar, unir pessoas, despertar a coragem para correr riscos com pouca preocupação com o fracasso e sucesso em si mesmo. Eles reforçam a confiança em si mesmo e nos outros, e todos podem participar autenticamente, onde ganhar e perder são apenas referências para o contínuo aperfeiçoamento pessoal e coletivo (BROTTO, 1997, p. 16) 
Outro modo de atender às demandas dos/as estudantes, incentivando-os a participarem juntos/as, independentemente do gênero, é proporcionar vivências e experiências através de jogos e esportes modificados e transformados, onde o objetivo é fazer com que os/as alunos/as pensem meios e maneiras diferentes de praticar um esporte (como por exemplo, o futebol), modificando regras, materiais a serem utilizados, números de participantes, enfim, para que todos/as possam participar de forma ativa. Assim, acaba facilitando o aprendizado dos movimentos, sua história e suas regras, além de garantir uma construção coletiva prazerosa (DARIDO; RANGEL, 2014).

A ideia de coabitar espaços de forma não excludente, aprender de forma prazerosa, entender aspectos sociais em relação às práticas corporais também poderá contribuir para que a consideração de aspectos formativos, em relação aos corpos, não fique apenas nas aulas de educação física.

\section{CONSIDERAÇões FINAIS}

Com base nos documentos e na literatura apresentados neste trabalho, verifica-se que a criação de uma modalidade específica para atender as especificidades do público jovem e adulto na educação foi uma ideia urgente e necessária, surgindo novas oportunidades para pessoas que não puderam, por algum motivo, iniciar ou terminar os estudos da educação básica, no tempo previsto na legislação educacional.

O papel do/a professor/a no processo de ensino-aprendizagem dos/as alunos/as é imprescindível, porém, temos que conhecer as dificuldades vivenciadas por eles e elas. Um problema presente na vida dos/as docentes responsáveis pela prática pedagógica educação física e que lecionam na EJA é a lei 9.394/96, art. 26, parágrafo 3, que traz a educação física como facultativa nos cursos noturnos em relação à parte prática, onde o/a aluno/a pode ser dispensado/a com base na lei acima citada, a qual refere-se a aspectos que atingem quase todo o público da EJA, afastando o alunado de estar presente nas aulas de educação física. Mesmo sendo possível realizar um trabalho com base na cultura, na realidade vivida por esses/as estudantes, trazendo questionamentos, reflexões e debates acerca de temas importantes para a formação desses/as alunos/as.

Durante a pesquisa, foi possível perceber que leis, diretrizes e instituições, como os PCNs, a LDB, o MEC, as CONAEs e a própria Constituição Federal enfatizam a questão da valorização das diferenças e o respeito mútuo entre as pessoas. O que está ligado diretamente com as questões de gênero. Entretanto, é essencial ressaltar o atual momento político que desvaloriza e deslegitima abordar as questões de gênero nas escolas, inibindo e desencorajando os/as professores/as a problematizarem esse assunto em suas aulas, seja por meio de projetos de lei municipais e estaduais que querem proibir a citação desse termo em ambiente escolar e, consequentemente, da retirada dos termos "gênero e orientação sexual" da educação em todo o território nacional. Partindo dessa perspectiva, há uma grande preocupação em relação ao futuro do trabalho inclusivo e crítico, da valorização das diferenças e da diversidade. O que afeta, diretamente, o que entendemos por corpo, pois essas atuais mudanças trazem o viés biológico como preponderante, com base na genitália, nos aspectos biológicos definindo a discussão. 
Ao percorrer uma concepção de educação que busca entender os sujeitos e seus contextos, o entendimento de gênero considera esses aspectos. Assim como muitas outras questões que estão fora do espaço escolar precisam e devem ser debatidas, em benefício dessa população explorada e excluída dos bens socialmente construídos, como a educação.

Visando estabelecer uma relação entre a EJA e as questões de gênero, que é objetivo e delimitação desse trabalho, nos debruçamos sobre três orientações curriculares municipais do Estado do Rio de Janeiro e, a inserção da abordagem sobre o gênero pela disciplina educação física na EJA. Verificamos que essas orientações - de municípios da região metropolitana, que foram das cidades de Tanguá, Belford Roxo e Rio de Janeiro - trazem e enfatizam a importância de diversidade e pluralidade cultural, valorização das diferenças e respeito ao próximo. Mesmo relatando que os temas transversais devem estar presentes nas aulas, apenas a orientação curricular do município do Rio de Janeiro destacou o termo gênero em seus documentos.

Também foram destacados conteúdos a fim de identificar essas questões na prática pedagógica, onde os jogos coletivos e cooperativos, conhecimentos sobre o corpo, a ludicidade, a recreação, a modificação de regras de acordo com as necessidades surgidas foram mencionadas como formas de auxiliar a enxergar a educação física escolar na EJA com um olhar diferente, numa perspectiva inclusiva, crítica e co-educativa.

Essa maneira nos ajuda a entender o corpo além do estritamente biológico, fortalecendo-o como produto e produtor sociocultural. Essa visão permite ao/à professor/a enfatizar sua intencionalidade pedagógica na valorização da diversidade e pluralidade de manifestações da cultura corporal, auxiliando na construção da autonomia e cidadania, de forma participativa e crítica.

Concluímos acreditando que as aulas de educação física podem colaborar para uma inicial mudança de pensamentos direcionados aos alunos e alunas da EJA, uma vez que esse público apresenta a especificidade do mundo do/a jovem e do/a adulto/a. Assim, as questões como a valorização das diferenças, o respeito ao próximo e um diálogo mais aberto, bem como a importância do coletivo em detrimento ao individual, enfatizando o pensamento crítico, podem ser caminhos para propiciar que cada um/a se identifique como sujeito do seu tempo, fruto de relações históricas e interpessoais, assim como produtor de transformações no contexto em que faz parte. E que essas ideias estão marcadas, expressas em nossos corpos.

A inclusão da temática gênero na EJA provoca um novo olhar, não somente para a educação física, mas para toda a comunidade escolar, pois convoca a problematizar questões recorrentes da nossa sociedade, em que muitos/as alunos/as, por terem uma formação hegemônica, acabam reproduzindo valores machistas e excludentes. Isso sugere que pesquisar esse assunto se faz importante, promovendo o interesse e ampliando as discussões e os olhares sobre o corpo em geral, no intuito de questionar e refletir questões sociais presentes em nosso cotidiano. E, o quanto promovem hierarquias e desigualdades.

Sem dúvidas, a formação continuada - como é relatado no documento da CONAE (BRASIL, 2010) -, seja em cursos de extensão, grupos de pesquisa e programas de pós-graduação, em muito contribui para questionar essa lógica, alargando a compreensão dos diferentes níveis e modalidades que constituem a escolarização, especialmente quando a 
formação inicial para a Educação de Jovens e Adultos ainda não é forte nas Universidades. Assim como as questões relacionadas ao corpo, como o gênero, não é algo restrito à licenciatura em educação física - afinal, os alunos e as alunas estão presentes, de maneira integral, em todas as aulas. Dentre os desdobramentos possíveis desse estudo, identificamos que pesquisar as diretrizes da formação docente será fundamental - como possibilidade de destacar a responsabilidade da formação pelas Universidades, assim como para agudizar o diálogo com as orientações direcionadas à educação básica.

\section{REFERÊNCIAS}

ALTMANN, Helena. Educação Física escolar: relação de gênero em jogo. São Paulo/SP: Cortez, 2015. 176 p. (Coleção educação \& saúde, v. 11).

ANTUNES, Alan; GEBRAN, Raimunda. A educação física no contexto escolar: trajetória e proposições pedagógicas. Revista Comunicações, Piracicaba/SP, ano 17, n. 1, p. 31-41, 2010.

BELFORD ROXO. Proposta Curricular: elementos centrais da Educação Física escolar na Educação de Jovens e Adultos do Ensino Fundamental. Belford Roxo/RJ: SME, 2012.

BRASIL. Base Nacional Comum Curricular. Brasília/DF: MEC, 2018. Disponível em: $<$ http://basenacionalcomum.mec.gov.br/images/BNCC_EI_EF_110518_versaofinal_site. pdf?utm_source $=$ Concursos + Educa $\% \mathrm{C} 3 \% \mathrm{~A} 7 \% \mathrm{C} 3 \% \mathrm{~A} 3 \mathrm{o}+\mathrm{F} \% \mathrm{C} 3 \% \mathrm{ADsica} \& u t m \_$campaign=75421679ab-EMAIL_CAMPAIGN_2020_07_30_07_13\&utm_medium=email\&utm_term=0_31efd746ae-75421679ab-362517906>. Acesso em: 30 jul.2020.

BRASIL. Conferência Nacional de Educação - CONAE. Brasília/DF: MEC, 2010. Disponível em: $<$ http://conae.mec.gov.br/images/2010/pdf/documentos/documento_final_ sl.pdf>. Acesso em: 31 jul.2020.

BRASIL. Conferência Nacional de Educação - CONAE. Brasília/DF: MEC, 2014. Disponível em: <http://conae2014.mec.gov.br/images/pdf/doc_referencia_conae2014.pdf > Acesso em: 31 jul.2020.

BRASIL. Constituição da República Federativa do Brasil. Brasília/DF: Senado Federal, 1988. Disponível em: <http://www.planalto.gov.br/ccivil_03/Constituicao/Constituicao. htm>. Acesso em: 29 jul.2020.

BRASIL. Diretrizes Curriculares Nacionais para a Educação Jovens e Adultos - Parecer CNE/CEB no 11/2000. Brasília/DF: MEC, 2000. Disponível em: <http://portal.mec. gov.br/cne/arquivos/pdf/PCB11_2000.pdf>. Acesso em: 28 jul. 2020.

BRASIL. Diretrizes Curriculares Nacionais para a Educação e Jovens e Adultos - Resolução CNE/CEB no 01/2000. Brasília/DF: MEC, 2000. Disponível em: <http://portal. mec.gov.br/cne/arquivos/pdf/CEB012000.pdf>. Acesso em: 28 jul. 2020. 
BRASIL. Diretrizes Operacionais para a Educação de Jovens e Adultos - Resolução CNE/CEB no 03/2010. Brasília/DF: MEC, 2010. Disponível em: <http://confinteabrasilmais6.mec.gov.br/images/documentos/resolucao032010cne.pdf $>$. Acesso em: 28 jul. 2020.

BRASIL. Educação Física na Educação de Jovens e Adultos. Brasília/DF: MEC, 2000. Disponível em: <http://portal.mec.gov.br/secad/arquivos/pdf/eja/propostacurricular/segundosegmento/vol3_edufisica.pdf>. Acesso em: 28 jul. 2020.

BRASIL. Lei de Diretrizes e Bases da Educação Nacional: Lei n. 9.394/96. Brasília/DF: MEC, 1996. Disponível em: <http://www.planalto.gov.br/ccivil_03/LEIS/L9394.htm>. Acesso em: 29 jul. 2020.

BRASIL. Parâmetros Curriculares Nacionais: Orientação Sexual. Brasília/DF: MEC, 1997. p. 72-110. Disponível em: <http://portal.mec.gov.br/seb/arquivos/pdf/livro102.pdf>. Acesso em: 29 jul. 2020.

BRASIL. Plano Nacional de Educação (PNE). Brasília/DF: MEC, 2014. Disponível em: $<$ http://pne.mec.gov.br/18-planos-subnacionais-de-educacao/543-plano-nacional-de-educacao-lei-n-13-005-2014>. Acesso em: 31 jul.2020.

BROTTO, Fábio. O. Jogos cooperativos: se o importante é competir, o fundamental é cooperar. Santos/SP: Re-novada, 1997.

BRUHNS. O corpo parceiro e o corpo adversário. $2^{a}$ ed. Campinas/SP: Papirus, 1999.

CARVALHO, Rosa Malena. Educação Física na Educação de Jovens e Adultos. Revista Lugares de Educação, Bananeiras/PB, v. 3, n. 5, p. 37-49, 2013.

CARVALHO, Rosa Malena. A cultura corporal como concepção que organiza a Educação Física e caracteriza o escolar. Teias, Rio de Janeiro/RJ, v. 18, n. 49, p. 253-268, 2017.

CARVAlHO, Rosa Malena; CAMARGO, Maria Cecília. Formação de professores em educação física e a educação de jovens e adultos. Movimento, Porto Alegre/RS, v. 25, e25029, p. 1-13, 2019.

COLETIVO DE AUTORES. Metodologia do Ensino de Educação Física. São Paulo/SP: Cortez Autores Associados, 1992.

DARIDO, Suraya; RANGEL, Irene (coords). Educação física na escola: implicações para a prática pedagógica. Rio de Janeiro/RJ: Guanabara Koogan, 2014.

LUCKESI, Cipriano. Educação, Ludicidade e Prevenção das Neuroses Futuras: uma Proposta Pedagógica a partir da Biossíntese. Ludopedagogia, Salvador/BA: UFBA/ FACED/ PPGE, v. 1, p. 9-42, 2000. 
MINAYO, Maria Cecília (Org). Pesquisa social: teoria, método, criatividade. Petrópolis/ RJ: Vozes, 2001.

OLIVIERA, Flávia; VOTRE, Sebastião. Bullying nas aulas de educação física. Movimento, Porto Alegre/RS, v. 12, n. 02, p. 173-197, 2006.

PEREIRA, Viviane; DEVIDE, Fabiano. Futebol como conteúdo generificado: uma possibilidade para rediscutir as relações de gênero. EFDeportes/Revista Digital, Buenos Aires, ano. 12, n. 118, p. 1-9, 2008.

RIO DE JANEIRO. Orientações Curriculares para o PEJA: Educação Física. Rio de Janeiro/RJ: SME, 2010.

SARAIVA, Maria do Carmo. Co-educação Física e Esportes: quando a diferença é mito. Ijuí/RS: Unijuí, 1999.

SCOTT, Joan. Gênero: uma categoria útil de análise histórica. Educação e Realidade, Porto Alegre/RS, v. 20, n. 2, p. 71-99, 1995.

SOUSA, Eustáquia; ALTMANN, Helena. Meninos e meninas: Expectativas corporais e implicações na educação física escolar. Cadernos Cedes, ano XIX, n. 48, p. 52-68, 1999.

TANGUÁ. Deliberação CME n 21/2012 para a EJA. Tanguá/RJ: SME, 2012.

\section{DADOS DOS AUTORES}

\section{Lucas Baptista Mousinho Lins}

Licenciado em Educação Física pela Universidade Federal Fluminense (UFF). lucaslins31@hotmail.com

\section{Rosa Malena de Araújo Carvalho}

Doutora em Educação pela Universidade do Estado do Rio de Janeiro (UERJ). Docente da Universidade Federal Fluminense (UFF). rosamalena@id.uff.br

Submetido em: 17-09-2020

Aceito em: 28-02-2021 